\title{
OESOPHAGEAL STENTING IN MALIGNANT DYSPHAGIA - FACTORS ASSOCIATED WITH DIFFERENT COMPLICATIONS AND THEIR EFFECT ON LONG-TERM PROGNOSIS
}

\author{
Parvinder Singh ${ }^{1}$, Ghansham Sharma ${ }^{2}$, Abhitesh Singh ${ }^{3}$, Anantbir Singh ${ }^{4}$, Parmod Kumar Bhatia 5 , Amarjit Singh Grover 6 \\ ${ }^{1}$ Assistant Professor, Department of Surgery, Gian Sagar Medical College and Hospital, Ramnagar, Rajpura. \\ ${ }^{2}$ Assistant Professor, Department of Biostatistics, ESIC Medical College and PGIMSR, Bangalore. \\ 3Junior Resident, Department of Surgery, Gian Sagar Medical College and Hospital, Ramnagar, Rajpura. \\ 4Junior Resident, Department of Surgery, Gian Sagar Medical College and Hospital, Ramnagar, Rajpura. \\ 5 Professor, Department of Surgery, Gian Sagar Medical College and Hospital, Ramnagar, Rajpura. \\ ${ }^{6}$ Professor, Department of Surgery, Gian Sagar Medical College and Hospital, Ramnagar, Rajpura.
}

\section{ABSTRACT}

\section{BACKGROUND}

Patients with oesophageal neoplasm usually present at very advanced stage of disease and in them palliation is the only way of treatment. Oesophageal stenting is a very reliable way of doing this. But it is seen that in spite of good relief of dysphagia, later on many complications can arise due to stenting.

The aim of this study was to look for these complications, factors related to these complications and their effect on prognosis of patients.

\section{MATERIALS AND METHODS}

We conducted a retrospective followup study. The data were obtained retrospectively from January 2012 to January 2015 from patients in which oesophageal stenting was done for malignancy.

\section{RESULTS}

We found that there was immediate relief of dysphagia with improvement in median dysphagia score from 3 to 1 after stenting. One patient had procedure-related major complication in the form of post-procedural bleed (after 16 days of stenting) leading to the death of that patient. Minor complications were present in 43 patients treated conservatively. These include regurgitation of gastric contents (40\%), pain after stenting (33\%), stent obstruction (24\%), stent migration (4.6\%) and bleed (2.2\%). All the minor complications were treated conservatively except in 5 patients in whom re-stenting was done. Regurgitation of food, stricture length, grade of dysphagia and position of the stent across the gastro-oesophageal junction were associated with different morbidities.

\section{CONCLUSION}

Oesophageal stenting is relatively a safe procedure with reliable relief of dysphagia, but there are many factors, both patients related and stent related which results in different complications. Further prospective and multicentre studies are needed to evaluate the role of an anti-reflux stent and other factors leading to poor prognosis even after stenting.

\section{KEYWORDS}

Oesophageal Neoplasm, Self-Expandable Metallic Stents (SEMS), Oesophageal Stenting, Gastro-Oesophageal Reflux.

HOW TO CITE THIS ARTICLE: Singh P, Sharma G, Singh A, et al. Oesophageal stenting in malignant dysphagia - factors associated with different complications and their effect on long-term prognosis. J. Evolution Med. Dent. Sci. 2016;5(101):7413-7417, DOI: $10.14260 /$ jemds/2016/1678

\section{BACKGROUND}

At time of presentation to a tertiary care centre, the majority of the patients of oesophageal neoplasm have already advanced disease and in this setting palliation is the only aim of treatment.[1,2] As patient usually presents with dysphagia, palliation of the dysphagia is the primary goal of treatment.[1,2] Although, there are many ways to relieve the dysphagia, but presently self-expanding metallic stenting is the treatment of choice to palliate it. ${ }^{[2,3,4]}$ There are different studies in literature citing different rates and types of complications

Financial or Other, Competing Interest: None.

Submission 11-11-2016, Peer Review 05-12-2016,

Acceptance 12-12-2016, Published 19-12-2016.

Corresponding Author:

Dr. Parvinder Singh,

\#23, Adjoining Taj Caterers,

Near First Gol Chakkar, Factory Area,

Patiala-147001, Punjab.

E-mail: drperrysingh@gmail.com

DOI: $10.14260 /$ jemds $/ 2016 / 1678$ after stenting. $[2,3,4,5]$ We performed this study with aim of identification of various complications after stenting and the proposed factors leading to these complications based on our observations and review of the literature and their effect on prognosis of the patient. This is the first of its kind study from this region.

\section{MATERIALS AND METHODS}

We conducted an exploratory hospital-based retrospective followup study. The data were obtained retrospectively from January 2012 to January 2015 with endoscopic biopsy proven carcinoma of the oesophagus patients, in whom oesophageal stenting was done. The sample size of the present study was calculated by referring dysphagia prevalence in oesophageal neoplasm patients, which was up to $86.4 \%$ as per literature. Taking $10 \%$ relative precision (allowable error) at $5 \%$ level of significance (alpha error) and using the formula 


$$
n=\frac{Z_{\alpha / 2}{ }^{2} P Q}{E^{2}}
$$

where $\mathrm{Z}_{\alpha / 2}$ is the standard normal variate for two-tailed hypothesis, $\mathrm{P}$ is the Dysphagia prevalence, $\mathrm{Q}=1-\mathrm{P}$ and $\mathrm{E}$ is the allowable error, the sample size was calculated to be 60 . But, we decided to include 100 patients in order to make the study powerful and more conclusive. But to remove the bias of comorbidities associated with carcinoma oesophagus, we included only patients who had metastatic or locally advanced carcinoma without any other comorbidity. Rest of the patients associated with some comorbidities was excluded from the group. A standard proforma was prepared to enter the data and then the data was thoroughly reviewed. To conduct this study, proper ethical clearance was taken. Stenting was performed by Gastro Surgery division of Department of Surgery of the Guru Gobind Singh Medical College, Faridkot, Punjab, India by a single surgeon. Inpatient admission records were analysed to acquire data on the patient demographic profile, tumour characteristics, stenting procedure, early and late complications and re-interventions. Success rate was determined by relief of symptoms before and after the stenting. Complications were noted down and these were thoroughly analysed to assess the factors associated with production of these complications and its effect on prognosis of the patient. Patients were followed till July 2015. After that followup was closed.

Proper consent from patient and relatives was taken before the procedure. All patients were evaluated by routine biochemistry, chest x-ray and ECG. Patients with associated medical morbidity were examined by the physician. Selfexpandable, metallic and covered stenting was done under sedation with endoscopy and fluoroscopy guidance. All patients were assessed by chest $x$-ray in lateral position on day 1 to know the position of the stent. If there was displacement of the stent, it was repositioned using endoscopy and fluoroscopy. Patients were allowed orally on day 2, so that stent could expand fully and make its place in the oesophagus. They were discharged on day 3 after oral acceptance of food except in those in which some sort of complication had arisen. All patients were followed after two weeks for review and later on as required. They all were sent for chemoradiotherapy.

\section{Statistical Analysis}

Qualitative data was expressed in terms of frequencies and percentages (proportions), whereas quantitative data as mean \pm SD. For the effect of the complications on the various prognostic factors has been quantified by conducting nonparametric chi-square test for independence of attributes. In order to have significant result, the $\mathrm{p}$-value $<0.05$ was considered as statistically significant value. Statistical analysis was carried out by using a statistical package IBM SPSS-20.

\section{RESULTS}

We had a total of 100 patients during this study period in which stenting was done, but as per inclusion criteria 13 patients were excluded who have other medical related problems like cardiac, respiratory or CVA. So we were left with 87 patients. There were 56 male patients and 31 females with mean age of presentation $64.5 \pm 9.39$ years (Mean \pm S.D.) with the range of 37 to 91 years; 75 patients presented with dysphagia with or without chest pain or a cough. Tumour was mainly in middle oesophagus (49 patients) followed by lower oesophageal tumour (34 patients). Only 4 patients had upper oesophageal carcinoma. Four patients had associated tracheo/bronchial-oesophageal fistula. Before coming to the hospital, they have symptoms since $5.8 \pm 3.0$ months (Mean \pm S.D.).

The mean length of stricture was $3.64 \pm 1.3 \mathrm{~cm}$ with the range of 2 to $8 \mathrm{~cm}$. Dysphagia was graded by MP score (Table I). In 76 patients, $11 \mathrm{~cm}$ long stent was used and in 11 patients $14 \mathrm{~cm}$ stent was used. Fluoroscopic guidance was required for patients having long stricture and having tracheo/bronchialoesophageal fistulas.

There was highly statistically significant relief of dysphagia after the stenting from median dysphagia score 3 to $1(p=.000)$. Patients having oesophago-tracheo-bronchial fistula responded very well to stenting and in all the 4 patients cough and dysphagia resolved within 72 hours.

Out of 87 patients 43 patients had some sort of complications and total of 91 complications occurred after the procedure (Table II).

Post procedure pain developed in 33.3\% (29/87) of patients and was the most common early complication. All except three patients had no change in stay, so it was not associated with any poor prognosis. But on intragroup analysis $14 / 21$ patients (of long stricture group; $>5 \mathrm{~cm}$ ), i.e. $66 \%$ had pain compared to $15 / 66$ (22\%) (short stricture; $<5$ $\mathrm{cm}$ ) had pain (Table III). It was highly statistically significant $\left(\mathrm{p}=.000^{\mathrm{HS}}\right)$. Also patients who had high-grade dysphagia (Grade 3 and 4 ) before stenting (24/29) had more pain. So high-grade dysphagia and stricture length were associated with post-operative pain.

Pain was followed by stent migration (4.6\%) and haematemesis (2.2\%). All migrations were within 24 hours of the procedure and these were corrected by re-endoscopy. There was no perforation during the procedure. Two patients had bleeding, out of which in one patient bleeding stopped spontaneously without any intervention or transfusion, while in one patient who was admitted 2 weeks after the procedure with marked anaemia and history of haematemesis received two units of packed red blood cells. In that patient, reendoscopy was done. As such no active bleed was seen. But that patient after one day of re-endoscopy bled again and could not be saved.

Late complications include regurgitation of gastric contents into oesophagus (40\%) and stent obstruction (24\%); 35 patients had regurgitation. Out of 24 patients who had stent across GE junction regurgitation was in 16 patients (66\%) and out of 63 patients who had stent above GE junction had regurgitation in 19 patients (30\%) and this was statistically significant $(\mathrm{p}=.002)$. Proton pump inhibitors and antiemetic (domperidone and metoclopramide) were given in these patients, but they did not appear to influence the symptoms of reflux, regurgitation or vomiting. So the patients who had stents across the GE junction had more regurgitation.

Stent obstruction occurred with mean duration of $4.28 \pm$ 1.78 months after the procedure and most common cause was growth (in 18 patients); 5 patients underwent re-stenting. All the patients who had re-stenting, they had growth proximal to the stent obstructing the stent opening.

47 patients died over the study period with average time of death being 5.9 months after the stenting and 30 patients 
were alive till the end of study; 10 patients lost to follow up. As they had some sort of complications, we included them in the study.

$25 / 45$ (55\%) of middle oesophageal growth and 19/29 (65\%) of lower oesophageal growth patients died (Table IV). Thus, survival was more in middle oesophageal tumour, although this difference did not reach statistical limits ( $p=$ $0.674 \mathrm{NS}$ ). As majority of patients (94) were of squamous cell carcinoma, so it could not be ascertained that histology has an impact on survival post stenting.

$12 / 18(66 \%)$ patients died during the study period who had recurrence of growth on either end as compared to 35/59 (59\%) patients who had no recurrence of growth and this was also not statistically significant $\left(\mathrm{p}=0.576^{\mathrm{NS}}\right.$ ) (Table V).

But in patients who developed regurgitation of food and vomiting after stenting had decreased survival; 22/31 (71\%) had regurgitation (patients who lost to follow up were not included in this statistical analysis), while 9 patients who had regurgitation are alive and 4 patients were lost to follow up (Table VI); while 25/46 (54\%) patients who had no regurgitation died. Although, this difference could not reach statistically significant limits ( $\left.p=0.142^{\mathrm{NS}}\right)$, but when we see the absolute difference this was significant (17\%). So clinically, we can say that patients with more regurgitation had more mortality. This needs further confirmation by increasing the sample size and doing well-designed prospective trials.

\begin{tabular}{|c|c|}
\hline Grade 0 & Normal Diet \\
\hline Grade I & Able to Swallow some Solid Foods \\
\hline Grade II & Able to Swallow only Semi-Solid Foods \\
\hline Grade III & Able to Swallow Liquids only \\
\hline Grade IV & Total Dysphagia \\
\hline \multicolumn{2}{|c|}{ Table I. MP Score } \\
\hline
\end{tabular}

\begin{tabular}{|c|c|}
\hline Complication & N (\%) \\
\hline • Pain & $29(33.3)$ \\
\hline $\begin{array}{l}\text { Severe Pain (stay }>7 \\
\text { days) }\end{array}$ & 03 \\
\hline - $\quad$ Migration & $04(4.6)$ \\
\hline - Haematemesis & $\begin{array}{l}02 \text { (1 mild }+1 \\
\text { severe; death) }\end{array}$ \\
\hline $\begin{array}{ll} & \text { Regurgitation of } \\
\text { food/vomiting }\end{array}$ & $35(40.2)$ \\
\hline - $\quad$ Post stenting obstruction & $21(24.1)$ \\
\hline$\circ \quad$ Proximal growth & 15 \\
\hline D $\quad$ Distal growth & 03 \\
\hline$\circ \quad$ Sheath disruption & 01 \\
\hline $\begin{array}{ll} & \begin{array}{l}\text { Food bolus } \\
\text { impaction }\end{array} \\
\end{array}$ & 02 \\
\hline Intervention & \\
\hline • $\quad$ Restenting & 05 \\
\hline - $\quad$ Dilatation & 14 \\
\hline - $\quad$ Removal of foreign body & 02 \\
\hline $\begin{array}{c}\text { Time of regrowth } \\
\text { (mean } \pm \text { SD, in months) }\end{array}$ & $4.28 \pm 1.78(1-8)$ \\
\hline Dead & $47(54)$ \\
\hline Alive & $30(34.5)$ \\
\hline Lost to follow up & $10(11.5)$ \\
\hline $\begin{array}{c}\text { Time of death, } \\
\text { mean } \pm \text { SD (in months) }\end{array}$ & $\begin{array}{c}5.94 \pm 3.10 \\
\text { (16 days to } 15 \\
\text { months })\end{array}$ \\
\hline \multicolumn{2}{|c|}{ Table II. Complications } \\
\hline
\end{tabular}

\begin{tabular}{|c|c|c|c|c|}
\hline $\begin{array}{c}\text { Stricture } \\
\text { Length } \\
\text { (in cm) }\end{array}$ & Present & Absent & Total & $\begin{array}{c}\text { Chi-Square } \\
\text { P-value }\end{array}$ \\
\hline $5-8$ & 14 & 7 & 21 & \multirow{2}{*}{$.000^{\mathrm{HS}}$} \\
\cline { 1 - 4 }-4 & 15 & 51 & 66 & \\
\cline { 1 - 4 } Total & $\mathbf{2 9}$ & $\mathbf{5 8}$ & $\mathbf{8 7}$ & \\
\cline { 1 - 1 } \\
Table III. Relation of Pain Based on Stricture Length \\
\hline
\end{tabular}

\begin{tabular}{|c|c|c|c|c|c|}
\hline $\begin{array}{c}\text { Site of } \\
\text { Growth }\end{array}$ & Alive & Dead & $\begin{array}{l}\text { Lost } \\
\text { to } \\
\text { F.U. }\end{array}$ & Total & $\begin{array}{c}\text { Chi-Square } \\
\text { P-value }\end{array}$ \\
\hline Upper & 01 & 02 & 01 & 03 & \multirow{4}{*}{$.674 \mathrm{NS}$} \\
\hline Middle & 20 & 25 & 04 & 45 & \\
\hline Lower & 10 & 19 & 05 & 29 & \\
\hline Total & 31 & 46 & 10 & 77 & \\
\hline \multicolumn{6}{|c|}{ Lost to follow up patients not included in the analysis } \\
\hline
\end{tabular}

\begin{tabular}{|c|c|c|c|c|}
\hline Re-Growth & Alive & Dead & Total & $\begin{array}{c}\text { Chi-Square } \\
\text { P-value }\end{array}$ \\
\hline Present & 6 & 12 & 18 & \multirow{3}{*}{$.576^{\mathrm{NS}}$} \\
\hline Absent & 24 & 35 & 59 & \\
\hline Total & 30 & 47 & 77 & \\
\hline \multicolumn{5}{|c|}{ Lost to follow up not included in the analysis } \\
\hline & $\begin{array}{r}\text { V.Mor } \\
\text { Recu }\end{array}$ & (1) & $\begin{array}{l}\text { ysis Ba } \\
\text { rowth }\end{array}$ & \\
\hline
\end{tabular}

\begin{tabular}{|c|c|c|c|c|c|}
\hline Regurgitation & Alive & Dead & $\begin{array}{c}\text { Lost to } \\
\text { F.U. }\end{array}$ & Total & $\begin{array}{c}\text { Chi-Square } \\
\text { P-value }\end{array}$ \\
\hline Present & 9 & 22 & 04 & 31 & \multirow{3}{*}{$.142^{\mathrm{NS}}$} \\
\hline Absent & 21 & 25 & 06 & 46 & \\
\hline Total & 30 & 47 & 10 & 77 & \\
\hline \multicolumn{6}{|c|}{ Lost to follow up not included in the analysis } \\
\hline Table VI. Mc & tolit & lnal & c $R g c$ & $n R e$ & Irgitation \\
\hline
\end{tabular}

\section{DISCUSSION}

Many factors influence survival in patients with oesophageal carcinoma. These include depth of tumour invasion, the extent of nodal and metastatic disease and the development of local complications like digestive-respiratory fistulae. Although, we could not control such factors, but one thing that was common in all was they had an inoperable disease with significant dysphagia. We already excluded those patients from our database that had other comorbidities like cardiovascular, respiratory or CNS along with oesophageal neoplasm.

Early relief of dysphagia after stenting is remarkable. Different studies showed around $80-100 \%$ improvement in dysphagia score. $[3,4,6,7]$ Our study also showed improvement in dysphagia score in $93 \%$ of patients consistent with other studies.

Chest pain is the main early complication after the stenting. It is usually mild and does not affect the quality of life or post-op stay in the hospital. Various series showed the variety of causes of chest pain. These include the degree of stricture at the time of stenting,[6] the expansible force of selfexpanding metallic stents ${ }^{[6,7]}$ and radiotherapy, ${ }^{[8]}$ but they did not affect the efficacy of stenting. In our series, high-grade dysphagia and long stricture length were associated with more pain.

There can be migration of stent after the procedure. It can be due to the use of covered stents as compared to uncovered 
stents, ${ }^{[6,8]}$ ingestion of ice cold liquids after stent insertion, $[8]$ the inability of the stent to fully expand $[6,8]$ and stents crossing the gastro-oesophageal junction. ${ }^{[9]}$ Early migration can be corrected easily by endoscopy and fluoroscopy. Although, stent migration is a technical issue, this does not affect the efficacy of stenting. In our series, all the patients who had stent migration had a lower oesophageal tumour and in all of them stent had crossed the GE junction. No stent migration occurred in upper and middle oesophageal tumour. So lower oesophageal tumours and tumours at gastro-oesophageal junction were also a significant factor towards stent migration and proper counselling of patient regarding this complication before stenting, especially in which tumour is present in lower oesophagus should be done.

Regurgitation of food and gastric juices is a troublesome symptom after stenting and patient thinks that stent is not working properly. Many series have pointed about this problem[9-11] but they have not commented on associated mortality. We, in our data, found that persons having more regurgitation of food materials had increased mortality as compared to patients who do not regurgitate after stenting. This may be due to reflux of gastric contents into tracheobronchial tree, especially after patient lies down. This can lead to pneumonia or other chest related complications in already immunocompromised and malnourished patient due to malignancy leading to increased mortality. This fact need to be further evaluated by prospective and well-designed studies and this may be the cause of poor prognosis. The use of antireflux stent or some modification of routine stent can be done to prevent this complication.

Food bolus obstruction also is one of the complication of stenting. But in various studies, it seems to be related not due to stent failure, but lack of patient education.[6,7] In our series three patients had food bolus impaction, which was managed by removing the bolus with the help of endoscopy. Dietary instructions should be given to patient and the relatives. Proper chewing of food, avoiding fibrous foods and increasing fluid intake and carbonated beverages and sometime dilute solution of hydrogen peroxide helps to enhance the passage of solid food through stent lumen.

Stent obstruction due to growth is a late complication of stenting. Although, its incidence has decreased with covered stents, but growth can occur proximal or distal to the stent and through the flanges. Maroju et al reported around 17 - 36\% incidence of re-growth after stenting. But they have not commented on incidence of mortality among re-growth patients.[12] Our series had $20 \%$ incidence of re-growth, but these patients had high mortality. As such this difference was not statistically significant, but if we see the absolute values they are clinically significant. So stent obstruction due to regrowth is also one of the factors related to poor prognosis.

While doing stenting, perforation of the oesophagus can occur. It may be due to over dilating an irregular or tight stricture or pre-procedure radio and chemotherapy treatment. Its incidence in various series is less than $5 \%$ with SEMS.[6,13] The decreasing diameter of delivery system makes perforation a rare occurrence and also covered stent (SEMS) covers the minor perforations during the procedure. ${ }^{[6,13,14]}$ In our series, no patient had oesophageal perforation. This could be because of the fact that we did not over-dilate the stricture, rather dilated to the extent that delivery system of the stent could negotiate across it.
In our series, 29/56 (51\%) male patients died and 18/31 (58\%) female patients died. So sex was not a statistical significant factor.

\section{Limitations of the Study}

This was a retrospective study in which stenting was done by single person and it was from single centre. This limits the exact interpretation of results on a community level. There is need to do multi-centered, well-designed, prospective and randomised studies to ascertain in which group of patients results are the best and how can we decrease the complication rate.

\section{CONCLUSION}

From this study, we concluded that although stenting immediately relieved the dysphagia in neoplasm patients, but later on many problems may arise with stenting which affects the efficacy of stenting. The factors which resulted in poor prognosis included position of stent across the GE junction leading to reflux of gastric contents freely into oesophagus and thus increase respiratory complications and malnutrition and thus mortality. This also leads to chances of migration of stent. Other factors leading to poor prognosis are long stricture and high-grade dysphagia, which can result in post-procedure pain. Male sex is associated with high mortality, but it is not statistically significant. Regrowth after stenting is also one of the poor prognostic factors for patient's survival as well as for stenting. We believe there is imperative need to undertake large-scale prospective, multicentre and well-designed randomised studies to compare different treatment modalities including stents incorporating an antireflux valve in patients with this devastating disease.

\section{REFERENCES}

1. Alsop BR, Sharma P. Esophageal cancer. Gastroenterol Clin North Am 2016;45(3):399-412.

2. Weigel TL, Frumiento C, Gaumintz E. Endoluminal palliation for dysphagia secondary to esophageal carcinoma. Surg Clin North Am 2002;82(4):747-61.

3. Dubecz A, Watson TJ, Raymond DP, et al. Esophageal stenting for malignant and benign disease: 133 cases on a thoracic surgical service. Ann Thorac Surg 2011;92(6):2028-32.

4. Gasparri G, Casalegno PA, Camandona M, et al. Endoscopic insertion of 248 prostheses in inoperable carcinoma of the esophagus and cardia: short-term and long-term results. Gastrointest Endosc 1987;33(5):354-6.

5. Neale JC, Goulden JW, Allan SG, et al. Esophageal stents in malignant dysphagia: a two-edged sword? J Palliat Care 2004;20(1):28-31.

6. Sarper $\mathrm{A}, \mathrm{Oz} \mathrm{N}$, Cihangir $\mathrm{C}$, et al. The efficacy of selfexpanding metal stents for palliation of malignant esophageal strictures and fistulas. Eur J Cardiothorac Surg 2003;23(5):794-8.

7. Ghazanfar S, Qureshi S, Tariq F, et al. Palliative management of irresectable carcinoma esophagus using self expandable metallic stent (SEMS). J Pak Med Assoc 2009;59(7):437-40.

8. Keller R, Flieger D, Fischbach W, et al. Self-expanding metal stents for malignant esophagogastric obstruction: experience with a new design covered nitinol stent. J Gastrointestin Liver Dis 2007;16(3):239-43. 
9. Coron E, David G, Lecleire S, et al. Antireflux versus conventional self-expanding metallic stents (SEMS) for distal esophageal cancer: results of a multicenter randomized trial. Endosc Int Open 2016;4(6):E730-6.

10. Philips P, North DA, Scoggins C, et al. Gastric-esophageal stenting for malignant dysphagia: results of prospective clinical trial evaluation of long-term gastroesophageal reflux and quality of life-related symptoms. J Am Coll Surg 2015;221(1):165-73.

11. North DA, Schlegel M, Martin RC. Gastroesophageal reflux disease-related symptom assessment in subjects with malignant dysphagia receiving esophageal stents. Am Surg 2014;80(12):1260-5.
12. Maroju NK, Anbalagan $P$, Kate $V$, et al. Improvement in dysphagia and quality of life with self-expanding metallic stents in malignant esophageal strictures. Indian J Gastroenterol 2006;25(2):62-5.

13. Nelson DB, Axelrad AM, Fleischer DE, et al. Siliconecovered wallstent prototypes for palliation of malignant esophageal obstruction and digestive-respiratory fistulas. Gastrointest Endosc 1997;45(1):31-7.

14. Felix VN, Caetano A, Cipullo JP, et al. Mid-esophagus unresectable cancer treated with a low cost stent. First experience. BMC Res Notes 2011;4:486. 